\section{SAT0178 THE EFFICACY AND SAFETY OF ANTI- PNEUMOCOCCAL VACCINATION IN SYSTEMIC LUPUS ERYTHEMATOSUS PATIENTS: SYSTEMATIC REVIEW AND META-ANALYSIS}

Mohammad Adawi ${ }^{1}$, Nicola Luigi Bragazzi ${ }^{2}$, Dennis Mcgonagle ${ }^{3}$, Naim Mahroum ${ }^{4}$ Giovanni Damiani ${ }^{5}$, Charlie Bridgewood ${ }^{3}$, Howard Amital ${ }^{4}$, Abdulla Watad $4 .{ }^{1}$ BarIlan University, Ramat Gan, Israel; ${ }^{2}$ University of Genoa, Genova, Italy; ${ }^{3}$ University of Leeds, Leeds, United Kingdom; ${ }^{4}$ Tel Aviv University, Tel Aviv-Yafo, Israel;

${ }^{5}$ Ospedale Maggiore, Milano, Italy

Background: Systemic lupus erythematosus (SLE) is a complex, multi-factorial chronic systemic autoimmune disease, characterized by a clinically relevant heterogeneity, affecting women more commonly than men. It has an estimated prevalence of 20 to 150 cases per 100,000 persons. The immune system dysregulation in SLE patients is associated with a higher risk of infections, including pneumococcal pneumonia. Anti-pneumococcal vaccines represent a valuable and effective preventative tool to mitigate and counteract pneumococcal pneumonia. However, the efficacy and safety of anti-pneumococcal immunization in SLE patients is both controversial and not completely agreed upon. Indeed, several epidemiological studies investigating the anti-pneumococcal vaccine safety and efficacy in patients suffering from SLE have reported short-term immunogenicity with elevated anti-pneumococcal antibody titres but inconsistent long-term findings, with some studies finding poor responses, mainly for long-term immune protection.

Objectives: We conducted a systematic review and meta-analysis to better understand the efficacy and safety of pneumococcal vaccination administered to SLE patients.

Methods: A comprehensive literature search in accordance with the "Preferred Reporting Items for Systematic Reviews and Meta-Analyses" (PRISMA) guidelines was performed. We mined also the gray literature and searched also for unpublished studies, presented at congresses either as oral communications or posters. We were able to identify 18 studies. All studies were designed as longitudinal investigations, 2, in particular, were of high quality, being randomized, double-blind trials. Four studies had control groups.

Results: Total sample size included 601 participants. Vaccine immunogenicity in terms of subjects with protective antibody titers ranged from $36 \%$ to $97.6 \%$. According to our systematic review and meta-analysis, high erythrocyte sedimentation rate (ESR), older age, earlier SLE onset, high disease activity, and immunosuppressive therapy were found to be statistically significant predictors of poor immunogenicity, although belimumab was found to have no significant impact. With regard to safety, no serious adverse events were found, with up to one third of cases reporting $\mathrm{mild} / \mathrm{low}$-grade complaints.

Conclusion: Due to the high risk of pneumococcal infection in SLE patients and given the safety and, at least partial, effectiveness, according to our systematic review and meta-analysis, in such patients, preventive strategies mainly by immunization, are required in all age groups and, in those needing immunosuppressive therapy, immunization should be given prior the initiation of the treatment.

Disclosure of Interests: Mohammad Adawi: None declared, Nicola Luigi Bragazzi: None declared, Dennis McGonagle Consultant for: Lilly, Novartis UCB, Speakers bureau: Lilly, Novartis UCB, Naim Mahroum: None declared, Giovanni Damiani: None declared, Charlie Bridgewood: None declared, Howard Amital Grant/research support from: Pfizer, AbbVie, Janssen, Grant/research support from: Pfizer, AbbVie, Janssen, Consultant for: Pfizer, Merck Sharp \& Dohme, Consultant for: Pfizer, Merck Sharp \& Dohme, Speakers bureau: Pfizer, Merck Sharp \& Dohme, Janssen, Sanofi, Bristol-Myers Squibb, Abbvie, Neopharm, Speakers bureau: Pfizer, Merck Sharp \& Dohme, Janssen, Sanofi, Bristol-Myers Squibb, Abbvie, Neopharm, Abdulla Watad: None declared

DOI: 10.1136/annrheumdis-2019-eular.3488

\section{SAT0179 CHANGE IN IMMUNOLOGICAL PARAMETERS DURING FOLLOW-UP OF PATIENTS WITH PRIMARY SJÖGREN'S SYNDROME: DATA FROM THE FRENCH ASSESS COHORT}

Paulina Szafors ${ }^{1}$, Cédric Lukas ${ }^{1}$, Jacques-Eric Gottenberg ${ }^{2}$, Xavier Mariette ${ }^{3}$, Bernard Combe ${ }^{1}$, Jacques Morel' ${ }^{1} .{ }^{1}$ University Hospital of Lapeyronie, Department of Rheumatology, Montpellier, France; ${ }^{2} \mathrm{CHU}$ Strasbourg-Hautepierre, Centre National de Référence des Maladies Autolmmunes Systémiques Rares, Service de Rhumatologie, Strasbourg, France; ${ }^{3}$ Hôpitaux Universitaire Paris-Sud, Department of Rheumatology, Kremlin Bicêtre, France

Background: Primary Sjögren's Syndrome (pSS) is associated with a biological panel of B-cell activity markers such as hypergammaglobulinemia, rheumatoid factor (RF), decreased C3/C4 complement, cryoglobulinemia, and an increase in $\beta 2$-microglobulin, used to calculate the biological domain of The EULAR Sjögren's Syndrome Disease Activity Index (ESSDAI). In $80 \%$ of patients, anti-nuclear autoantibodies, especially anti-Ro/ SSA and anti-La/SSB, are also observed. The change in these biological tests during follow-up of pSS patients has been poorly investigated.

Objectives: The objectives of our study were to assess the change in immunological parameters during the follow-up of pSS and to analyse the association with the clinical evolution.

Methods: We analysed data from the French prospective multicenter ASSESS cohort, including 395 patients with pSS. Clinical and biological data were collected at the baseline, then annually. Patients were included if at least two biological assessments and concomitant ClinESSDAl activity scores were available, based on standardized clinical evaluations of the patients. Anova, Wilcoxon and Chi-square tests were used to analyse the relationship between the clinical evolution and immunological profile. A p-value $\leq 0.05$ was considered as statistically significant.

Results: 362 of 395 patients had required data to allow their inclusion The mean number of visits was 5.5 . In $81.7 \%$ of patients, the biological status did not change throughout the 5 -year follow-up (Table 1). The clinical evolution was not related to the immunological changes observed between the previous two visits $(\mathrm{p}=0.30)$. There was no significant difference between the number of abnormal immunological markers and the ClinESSDAl activity score $(p=0.437)$ at the same visit. Disease activity according to the ClinESSDAI score remained stable in 257 patients (out of 351 with available data) during follow-up. 175 patients (49.8\%) were in remission and $82(23.3 \%)$ had an active disease. The number of abnormal biological markers at baseline was associated with subsequent clinical evolution: detection of $>5$ B-cell activity markers at baseline was a bad prognostic marker, (present in $12.4 \%$ of patients having persistent disease activity, versus $3.6 \%$ among patients with clinical favourable outcome) $(p=0.04)$.

Conclusion: The biological profile of pSS patients is usually stable over time, especially if the initial assessment is negative, but a higher immunological activity profile might be a bad prognostic factor. Changes in biological parameters do not predict the subsequent clinical course. In conclusion, it is not relevant to systematically repeat the complete immunological screening in pSS patients.

Table 1: Immunological variations during the follow-up of patients from the ASSESS cohort
\begin{tabular}{|l|l|l|l|}
\hline Immunological markers & $\begin{array}{l}\text { Number of patients with } \\
\text { positive marker at } \\
\text { baseline, } \boldsymbol{n}(\%)\end{array}$ & $\begin{array}{l}\text { Negative to } \\
\text { positive }\end{array}$ & $\begin{array}{l}\text { Positive to } \\
\text { negative }\end{array}$ \\
\cline { 3 - 4 } & $37 / 63(58.7)$ & $12(19.0)$ & $2(3.1)$ \\
\hline Rheumatoid factor & $58 / 323(17.9)$ & $24(7.4)$ & $24(7.4)$ \\
\hline Cryoglobulinemia & $109 / 337(32.3)$ & $5(1.5)$ & $32(9.5)$ \\
\hline Hypergammaglobulinemia & & $3(0.9)$ & $0(0.0)$ \\
\hline Hypogammaglobulinemia & $2 / 337(0.6)$ & $3(9.0)$ & $2(8.0)$ \\
\hline $\begin{array}{l}\text { B2-microglobuline } \\
22.3 \mathrm{mg} / \mathrm{L}\end{array}$ & $12 / 25(48.0)$ & $10(11.5)$ & $1(1.1)$ \\
\hline $\begin{array}{l}\text { C3 Complement } \\
\text { s0,80mg/L }\end{array}$ & $11 / 87(12.6)$ & $7(8.2)$ & $1(1.1)$ \\
\hline $\begin{array}{l}\text { C4 Complement } \\
\text { s0,15mg/L }\end{array}$ & $12 / 85(6.4)$ & $27(13.3)$ & $9(4.4)$ \\
\hline ANA $21 / 80 U I / L$ & $151 / 203(74.4)$ & $10(5.3)$ & $2(1.0)$ \\
\hline Anti-SSA positivity & $110 / 189(58.2)$ & $7(3.9)$ & $13(7.2)$ \\
\hline Anti-SSB positivity & $69 / 179(38.5)$ & $45(17.7)$ & $16(6.3)$ \\
\hline Monoclonal gammapathy & $37 / 254(3.9)$ & & \\
\hline
\end{tabular}

Disclosure of Interests: Paulina Szafors: None declared, Cédric Lukas: None declared, Jacques-Eric Gottenberg Grant/research support from: Bristol-Myers Squibb, Grant/research support from: Bristol-Myers Squibb, Consultant for: Bristol-Myers Squibb, Lilly, Pfizer, Sanofi-Genzyme, UCB Pharma, Consultant for: Bristol-Myers Squibb, Eli Lilly, UCB, Sanofi-Genzyme, Pfizer, Xavier Mariette Grant/research support from: Servier, Consultant for: AstraZeneca, Bristol-Myers Squibb, GlaxoSmithKline, Janssen, Pfizer, UCB Pharma, Bernard Combe Consultant for: Abbvie, Bristol-Myers Squibb, Gilead, Janssen, Eli Lilly, MSD, Novartis, Pfizer, Roche-Chugai, Sanofi, UCB, Jacques Morel: None declared DOI: 10.1136/annrheumdis-2019-eular.2241 